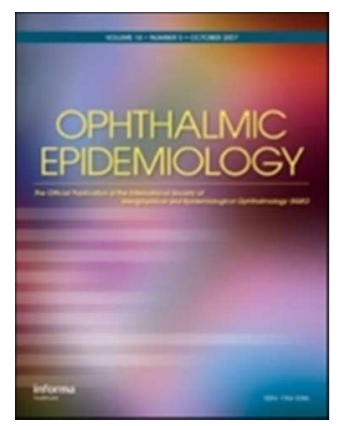

\title{
Trends in Cataract Surgical Rate and Resource Utilization in Egypt
}

\begin{tabular}{|r|l|}
\hline Journal: & Ophthalmic Epidemiology \\
\hline Manuscript ID & NOPE-2017-0090 \\
\hline Manuscript Type: & Original Research \\
\hline Date Submitted by the Author: & 24-Apr-2017 \\
\hline Complete List of Authors: & $\begin{array}{l}\text { Elbeih, Islam; National Eye Centre } \\
\text { Bascaran, Covadonga; London school of Hygiene and Tropical Medicine, } \\
\text { International Centre for Eye Health } \\
\text { Blanchet, Karl; London School of Hygiene and Tropical Medicine } \\
\text { Foster, Allen; London School of Hygiene and Tropical Medicine }\end{array}$ \\
\hline Keywords: & $\begin{array}{l}\text { Cataract, Cataract Surgical Rate, Egypt, Resouce Utilization, Service } \\
\text { Provision }\end{array}$ \\
\hline &
\end{tabular}

SCHOLARONE ${ }^{m}$

Manuscripts 


\section{Trends in Cataract Surgical Rate and Resource Utilization in Egypt}

Islam Elbieh ${ }^{1}$

Covadonga Bascaran ${ }^{2}$

Karl Blanchet ${ }^{2}$

Allen Foster ${ }^{2}$

${ }^{1}$ National Eye Centre, Cairo, Egypt

${ }^{2}$ London School of Hygiene \& Tropical Medicine, Keppel Street, WC1E 7HT, London

Islam Elbeih islamelbeih@gmail.com

Covadonga Bascaran Covadonga.Bascaran@Ishtm.ac.uk

Karl Blanchet Karl.Blanchet@lshtm.ac.uk

Allen Foster Allen.Foster@Ishtm.ac.uk

Financial support: this research was funded by the Kirkpatrick Scholarship, awarded to the first author by the London School of Hygiene and Tropical Medicine.

None of the following authors has any proprietary interests or conflicts of interest related to this submission

This submission has not been published anywhere previously and is not simultaneously being considered for any other publication.

\section{Corresponding author details:}

Islam Elbieh

islamelbeih@gmail.com

National Eye Centre, Cairo, Egypt 


\begin{abstract}
Purpose:

To evaluate cataract services in Egypt and assess resources and practices in public and private sector.

Methods:

The study was conducted between June and August 2015. All facilities in the country providing cataract services were contacted to obtain information on surgeries performed in 2014. Hospitals performing eye surgery in Quena, Sharkia, and Fayoum regions were visited and a questionnaire on resources for cataract surgery was completed.
\end{abstract}

\title{
Results:
}

Cataract surgery was offered in the public sector by 64 government and 16 university teaching hospitals and in the private sector by 101 hospitals. In 2014, the national CSR was 3,674 varying in governorates from 7,579 in Ismailia to 402 in Suez. The private sector performed $70 \%$ of cataract surgeries.

Analysis of 3 regions showed an $11.7 \%$ increase in cataract output between 2010 and 2014. The average number of cataract surgeries per unit in 2014 was 2,272 in private, 1,633 in university and 824 in government hospitals. Private hospitals had $60 \%$ of human resources for eye care. Phacoemulsification was the surgical technique in $85.6 \%$ of private, $72.1 \%$ of university and $41 \%$ of government hospitals. Reasons explaining the differences in output between public and private sectors were the lack of trainers, supervisors and incentives. 


\section{Conclusion:}

The private sector provides most of the cataract services in Egypt, resulting in inadequate services for the poor. There is a 15 fold variation in CSR between the best and least served regions. The public sector could increase cataract output by improving training, supervision and incentives. 


\section{Background}

Cataract is the main cause of blindness worldwide affecting an estimated 20 million people. ${ }^{1}$ As such, it is a priority of the WHO Global Action Plan 2014-19, (GAP) for Universal Eye Health. Cataract Surgical Rate (CSR) and Cataract Surgical Coverage (CSC) are two key indicators to monitor the progress of the GAP towards reducing the prevalence of vision impairment. ${ }^{2}$

Egypt is classified as a low / middle income country (LMIC) by the World Bank. ${ }^{3}$ In 2014 , the percentage of GDP spent on Health was $5 \%$, less than other neighboring countries such as Sudan (7.2\%), Morocco $(6.4 \%)$, Tunisia (7\%). ${ }^{4}$ The out-of-pocket (OOP) expenditure as a percentage of total health expenditure (THE) was $60 \%$ in 2010 compared with $7 \%$ in Morocco, 35\% in Tunisia, and $15 \%$ in Algeria. ${ }^{4} \mathbf{5}$ The high OOP indicates inadequate financial protection for poor people and the presence of financial barriers to access health services. ${ }^{6}$

The CSR is defined as the number of cataract surgeries performed per million population per year. ${ }^{7}, 8$ In Egypt, the national CSR was estimated to be 692 in 2005, less than Sudan (932), Tunisia (1329), and Libyan Arab Jamahiriya (1887) in the same year. ${ }^{9}$

As a national policy, cataract surgical services are provided for free in public hospitals for all patients eligible for National Health Insurance and Social Insurance. ${ }^{\mathbf{1 0}}$

The aim of this study in Egypt was to evaluate the coverage of cataract services over time and by region, and to assess the availability of key resources and practices in both public and private sectors of cataract service delivery. 


\section{Methods and Analysis}

The study was conducted between June and August 2015. All facilities in the country providing cataract surgical services were included and contacted by phone by the research team to obtain information on cataract surgeries performed in 2014

All hospitals performing eye surgery in three regions representing different geographical art s (Quena, Sharkia, and Fayoum) were visited and a detailed questionnaire of the availability and utilization of resources for cataract surgery was completed by the re earch team.

All private and public facilitic in the country providing cataract surgical services were included in the CSR calcula ion for 2014.

Quantitative data were entered usins MS Excel ${ }^{\circledR}$ and analyzed by using STATA $11^{\circledR}$. The CSR was calculated using pop vlation projections for 2014 from the Ministry of Health based on the latest census (2006). ${ }^{9}$

Qualitative data from the interviews was extracte from written notes and major themes were identified. Twelve eye care managers wo re interviewed, 5 from government, 2 from university and 5 from private hospita's.

Ethical approval was obtained from The National Eye Health office in the Ministry of Health in Egypt and the London School of Hygiene \& Tropical Medicine. 


\section{Results}

\section{National and Regional Cataract Data}

Cataract surgery is offered by 80 public hospitals - 64 government, 16 university hospitals - and 101 private sector hospitals.

The response rate for the nationwide questionnaire was $90.6 \%$ (164 of 181 hospitals) with $100 \%$ government (64) and university (16) hospitals responding and $83.2 \%$ of private sector hospitals ( 84 of 101 ). The distribution of the hospitals by sector and governorate is shown in (Figure 1).

In 2014 , a total of 317,181 cataract operations were reported to have been performed in Egypt of which $70.5 \%$ were in the private sector, $17.4 \%$ in government hospitals and $12.2 \%$ in university hospitals.

The National CSR was 3,674 per million population varying from 7,579 in Ismailia governorate to 402 in Suez. The Regional CSR is presented in Table 1 and Figure 2.

\section{Analysis of Cataract Services in three Regions (2010-2014)}

\section{Cataract output}

Data from 23 eye care facilities in three regions (Sharkia (11), Fayoum (8) and Quena (4) were analyzed. There was an $11.7 \%$ increase in the cataract output from $2010(32,533)$ to $2014(36,364)$ despite a decrease in $2011(29,338)$. The CSR shows a decline of more than $10 \%$ in all 3 Regions in 2011 (Figure 3).

The average number of cataract surgeries per unit in 2014 was 2,272 in private hospitals, 1,633 in university hospitals and 824 in government hospitals. Of the 43,752 cataract operations performed in the 3 regions in $201457.4 \%$ were on men. 


\section{Resources for Cataract Services}

Approximately $60 \%$ of the total human resources for eye care were working in private hospitals, $23 \%$ in the government hospitals, and $17 \%$ in university hospitals. The distribution of eye care workers by cadre in the three sectors is shown in Table 2. Fayoum had 28 ophthalmologists/million pop compared with Sharkia 26 and Quena 13. The average working day in private hospitals was 6.8 hours compared with 4.0 in university and 3.8 in government facilities.

Private and university hospitals were better equipped with operating theatre equipment than government hospitals. (Table 3).

\section{Cataract Surgery Practices}

Phacoemulsification was the surgical technique in $85.6 \%$ of private, $72.1 \%$ of university and $41 \%$ of government hospitals. Extra Capsular Cataract Extraction (ECCE) was the most common technique in government hospitals (59\%). The relatively low number of phacoemulsification cases in the government hospitals was due to either the absence of functioning phacoemulsification machines or absence of trained surgeons. Small Incision Cataract Surgery (SICS) was not practiced in any of the visited hospitals.

The private hospitals had the shortest average surgical time per case (approx. 8 mins) and turnaround time (16 minutes/case), compared with approx. 28mins and 37 mins in government hospitals. (Figure 4)

\section{Surgeons and Managers perspectives on cataract services}

Ophthalmologists $(n=22)$ from government and university hospitals were interviewed regarding provision of cataract services. The two main reasons given 
for the differences in output and practices between public and private sectors were the lack of trainers and supervision (15 of 22) and the lack of incentives (12 of 22). Lack of equipment was reported as the main reason for the lower number of phacoemulsification cases in the government and university hospitals. Most managers in government and university hospitals were not satisfied with the quantity and quality of the cataract services. Lack of government financial and technical support were the major challenges mentioned. They also expressed the need to improve the training programmes and update the hospital's equipment. On the other hand, most managers in the private hospitals were satisfied with the cataract services provided. 


\section{Discussion}

There are an estimated 2,400 ophthalmologists in Egypt, 30 per million population. ${ }^{\mathbf{1 1}}$ This is higher than other Middle East countries and the VISION2020 recommendations. ${ }^{\mathbf{1 2}}$

The CSR in 2014 in Egypt is estimated to be 3,674 per million population. This includes cataract surgeries performed in both public and private sectors. The study included $90.6 \%$ of all providers of cataract surgery and most of the remaining centers are small or non-functioning units and therefore unlikely to significantly affect the CSR calculation. The previous CSR estimate for Egypt was 692 in 2005-giving a 4-5 times increase in CSR over the last 9 years. ${ }^{\mathbf{1 3}}$ Although this would suggest a significant progress, the 2005 number may be underestimated as the methodology used in 2005 is not explicit about whether both sectors were included. Our survey showed that, in 2014, the private sector was responsible for over $70 \%$ of the cataract surgeries in Egypt.

There were marked differences in CSR between regions, ranging from 402 in Suez to 7,579 in Ismailia. In low and middle income countries, most eye hospitals and ophthalmologists offering cataract surgery are based in urban areas. ${ }^{13}$ Similarly, in our study, regions with large cities and a higher proportion of urban population, like Cairo, Giza, Ismailia, and Alexandria, showed higher CSR figures.

The target CSR of a given population is determined by the incidence of operable cataract, which is mainly influenced by the age structure of the population and the threshold of visual impairment used for performing cataract surgery. ${ }^{8}$ The target CSR for Egypt is likely to increase due a progressively ageing population 
and the lowering of the visual acuity threshold used as the indication of cataract surgery.

When analyzing three Regions over five years, there was an overall increase in cataract output of $14.6 \%$ from 2009 to 2014 ; however, there was a considerable decrease of the CSR in 2011, particularly in the private sector. This sharp decline is probably due to the uprising and revolution in Egypt in 2011 and the accompanying economic instability and political unrest.

VISION 2020 and the WHO Global Action Plan for Universal Eye Health promote the development and equitable distribution of human resources to achieve the optimum outcome in eye care delivery. ${ }^{\mathbf{2 , 1 4}}$ In all three Regions analysed, the private sector was more productive, better equipped and the staff had greater work satisfaction. Phacoemulsification surgery is ubiquitous in the private sector but not in the government sector. Egypt is transitioning from ECCE to phaco without adopting SICS. This is the same pattern that high income countries have followed. ${ }^{\mathbf{1 5}}$ In Egypt phaco outside the private sector is still not widespread, due to the cost of equipment and consumables. Conversely, in other middle-income countries SICS is now the routine technique. It is superior to ECCE in results and matches those of phaco at a lower cost. ${ }^{16}$ Re-training surgeons from ECCE to SICS could be faster and less costly than training them to do phaco, and it would mean that patients outside the private sector would be offered a technique with comparable results, however whether this is acceptable to the profession has to be considered. The alternative is a considerable investment to supply public sector hospitals with the training, equipment and consumables to perform routinme phacoemulsification cataract surgery. 
Gender inequity in access to cataract surgery has been shown in low-income settings, with a higher cataract surgical coverage for males than for females. ${ }^{17}$, 18. In our study in the three regions evaluated females accounted for $43 \%$ of cataract surgeries. In general women in LMICs are poorer and have less access to health services than men. ${ }^{19}$ In our study this was confirmed by the fact that gender inequity was more marked in the private sector.

\section{Conclusion}

In conclusion, determining CSR has given a better understanding of the geographic distribution of cataract services in Egypt. Civil unrest had an impact on provision of cataract services.

Relying on the private sector to provide the majority of cataract services may result in inadequate services for the poor if they cannot afford the cost of the surgery. Further research should focus on the quality of cataract surgical outcomes and interventions that can improve the utilization and productivity of resources available for cataract services. 


\section{References}

1. Pascolini D, Mariotti SP. Global estimates of visual impairment: $2010 . \mathrm{Br} J$ Ophthalmol. 2012;96(5):614-618.

2. WHO. Global Initiative for the Elimination of Avoidable Blindness : action plan 2006-2011. World health Organization, 2007 ISBN 9789241595889

3. World Bank. [cited 2015 08/02]; Available from: http://data.worldbank.org/country/egypt-arab-republic.

4. World Bank, Health expenditure, total (\% of GDP) [cited 2015 16/02]; Available from: http://data.worldbank.org/indicator/SH.XPD.TOTL.ZS.

5. Bethesda M. National Health Accounts 2007/2008: Egypt. Ministry of Health, Egypt, and Health Systems 20/20 project, September 2010.

6. Saksena P, Hsu J, Evans DB. Financial risk protection and universal health coverage: evidence and measurement challenges. PLoS Med. 2014;11(9):e1001701.

7. Foster A. VISION 2020: the cataract challenge. Community Eye Health Vol. 13 No. 342000 pp $17-19$.

http://www.cehjournal.org/article/vision-2020-the-cataract-challenge.

8. Lewallen S, Williams TD, Dray A, Stock BC, Mathenge W, Oye J, Nkurikiye J, Kimani K, Muller A, Courtright P. Estimating incidence of vision-reducing cataract in Africa: a new model with implications for program targets. Arch Ophthalmol. 2010;128(12):1584-1589.

9. WHO. Global Initiative for the Elimination of Avoidable Blindness : action plan 2006-2011. World health Organization, 2007 ISBN 9789241595889

10. Nakhimovsky S, Douglas Glandon, Nadwa Rafeh, Nagwan Hassan. Egypt National Health Accounts: 2008/09. Bethesda, MD: Health Systems 20/20 project, Abt Associates Inc. November 2011. 
11. International Council of ophthalmology, Number of Ophthalmologists in Practice and Training Worldwide [cited 2015 February 2nd]. Available from: http://www.icoph.org/ophthalmologists-worldwide.html.

12. Mediterranean WHO-ROftE. Implementation of VISION 2020 in the Eastern Mediterranean Region Cairo: 2004.

13. Brian G, Taylor H. Cataract blindness: challenges for the 21st century. Bull World Health Organ. 2001;79(3):249-256.

14. Adepoju FG, Ayanniyi AA, Pam V, Akanbi TB. Human resource development for Vision 2020 in developing countries: a change from absolute numbers. Eur J Ophthalmol. 2010;21(6):820-825.

15. Tabin G, Chen M, Espandar L. Cataract surgery for the developing world. Current opinion in ophthalmology. $2008 ; 19(1): 55-9$

16. Aravind S, Haripriya A, Taranum BSS. Cataract surgery and intraocular lens manufacturing in India. Curr Opin Ophthalmol. 2008;19(1):60-65.

17. Lewallen S, Courtright P. Gender and use of cataract surgical services in developing countries. Bull World Health Organ. 2002;80(4):300-303.

18. Rao GN, Khanna R, Payal A. The global burden of cataract. Curr Opin Ophthalmol. 2011;22(1):4-9.

19. Puentes-Markides C. Women and access to health care. Social Science \& Medicine. 1992;35(4):619-626. 


\section{List of Tables}

Table 1: CSR in Egypt by governorate in 2014

Table 2: Distribution of Human Resources by Cadre in 3 Regions

Table 3: Distribution of equipment by type of eye care unit 


\section{List of Figures}

Figure 1: Distribution of participating eye hospitals per governorate and sector

Figure 2: GIS map of Egypt showing distribution of CSR in 2014

Figure 3: CSR in three regions 2010-2014

Figure 4: Turnaround time and Cataract surgical rate in the government, university and private hospitals 
Table 1: CSR in Egypt by governorate in 2014

\begin{tabular}{lccc}
\hline \multicolumn{1}{c}{ Region } & Cataract & Population (mills) & CSR 2014 \\
\hline Ismailia & 8928 & 1.178 & 7579 \\
Cairo & 65097 & 9.278 & 7016 \\
Alexandria & 29074 & 4.812 & 6042 \\
Giza & 38999 & 7.585 & 5142 \\
Portsaid & 3406 & 0.666 & 5114 \\
Luxour & 5584 & 1.147 & 4868 \\
Dakahlia & 26041 & 5.949 & 4377 \\
Aswan & 6170 & 1.431 & 4312 \\
Sharkia* & 26746 & 6.485 & 4124 \\
Gharbia & 17416 & 4.751 & 3666 \\
Damietta & 4702 & 1.33 & 3535 \\
Fayoum* & 9126 & 3.17 & 2879 \\
Menofya & 11229 & 3.941 & 2849 \\
Menya & 13919 & 5.156 & 2700 \\
\hline Quena* & 7879 & 3.045 & 2588 \\
\hline Assyuit & 9430 & 4.245 & 2221 \\
Banisuef & 6118 & 2.856 & 2142 \\
Kfrelshikh & 5560 & 3.172 & 1753 \\
Qualiopia & 8159 & 5.106 & 1598 \\
Behira & 8004 & 5.804 & 1379 \\
Sohag & 5344 & 4.603 & 1161 \\
Suez & 250 & 0.622 & 402 \\
\hline Total & $\mathbf{3 1 7 , 1 8 1}$ & $\mathbf{8 6 . 3 4 2}$ & $\mathbf{3 6 7 4}$ \\
\hline & & & \\
\hline
\end{tabular}

*Three Regions evaluated in depth 
Table 2: Distribution of Human Resources by Cadre in 3 Regions

\begin{tabular}{|c|c|c|c|c|c|c|}
\hline \multirow[t]{2}{*}{ Cadre } & \multicolumn{2}{|c|}{$\begin{array}{c}\text { Government } \\
\begin{array}{c}\text { Hospital } \\
N=5\end{array}\end{array}$} & \multicolumn{2}{|c|}{$\begin{array}{c}\text { University } \\
\text { Hospitals } \\
\quad N=2\end{array}$} & \multicolumn{2}{|c|}{$\begin{array}{c}\text { Private } \\
\text { Hospitals } \\
\text { (N=16) }\end{array}$} \\
\hline & $\begin{array}{l}\text { No. } \\
69\end{array}$ & $\begin{array}{c}\text { No./unit } \\
13.8\end{array}$ & $\begin{array}{l}\text { No. } \\
56\end{array}$ & $\begin{array}{c}\text { No./unit } \\
28.0\end{array}$ & $\begin{array}{l}\text { No. } \\
168\end{array}$ & $\begin{array}{c}\text { No./unit } \\
10.5\end{array}$ \\
\hline $\begin{array}{l}\text { Ophthalmologists doing } \\
\text { cataract operations }\end{array}$ & 45 & 9.0 & 55 & 27.5 & 126 & 7.9 \\
\hline Anesthesiologists & 7 & 1.4 & 5 & 2.5 & 22 & 1.4 \\
\hline Operating Theatre nurses & 23 & 4.6 & 17 & 8.5 & 54 & 3.4 \\
\hline General nurses & 54 & 10.8 & 24 & 12.0 & 107 & 6.7 \\
\hline Administrative staff & 82 & 16.4 & 54 & 27.0 & 258 & 16.1 \\
\hline Maintenance Technicians & 4 & 0.8 & 2 & 1.0 & 20 & 1.2 \\
\hline
\end{tabular}


Table 3: Distribution of equipment by type of eye care unit

\begin{tabular}{|c|c|c|c|}
\hline Equipment & $\begin{array}{c}\text { Number I } \\
\text { govern. unit }\end{array}$ & $\begin{array}{c}\text { Number I } \\
\text { university unit }\end{array}$ & $\begin{array}{l}\text { Number / } \\
\text { private unit }\end{array}$ \\
\hline Number of beds & 6.6 & 10.0 & 4.9 \\
\hline \multicolumn{4}{|l|}{ Clinic Equipment } \\
\hline Slit lamp & 3.0 & 5.7 & 2.7 \\
\hline Tonometer & 1.4 & 2.0 & 2.0 \\
\hline Direct Ophthalmoscope & 2.2 & 3.5 & 2.0 \\
\hline Indirect Ophthalmoscope & 1.6 & 3.5 & 2.0 \\
\hline Trial lens set & 3.0 & 4.5 & 2.6 \\
\hline Auto refractor & 1.4 & 2.5 & 1.6 \\
\hline A scan & 0.8 & 1.0 & 1.1 \\
\hline Keratometer & 0.8 & 1.0 & 1.1 \\
\hline \multicolumn{4}{|c|}{ Operating Theater Equipment } \\
\hline Operating Theatre & 2.2 & 5.5 & 2.7 \\
\hline Operating Microscope & 2.0 & 4.0 & 3.0 \\
\hline Operating table & 2.4 & 5.5 & 3.0 \\
\hline Cataract surgical set & 4.8 & 13.0 & 9.1 \\
\hline Phaco machine & 0.8 & 3.0 & 2.4 \\
\hline Vitrectomy machine & 0.4 & 2.0 & 1.4 \\
\hline
\end{tabular}


Figure 1: Distribution of participating eye hospitals per governorate and sector

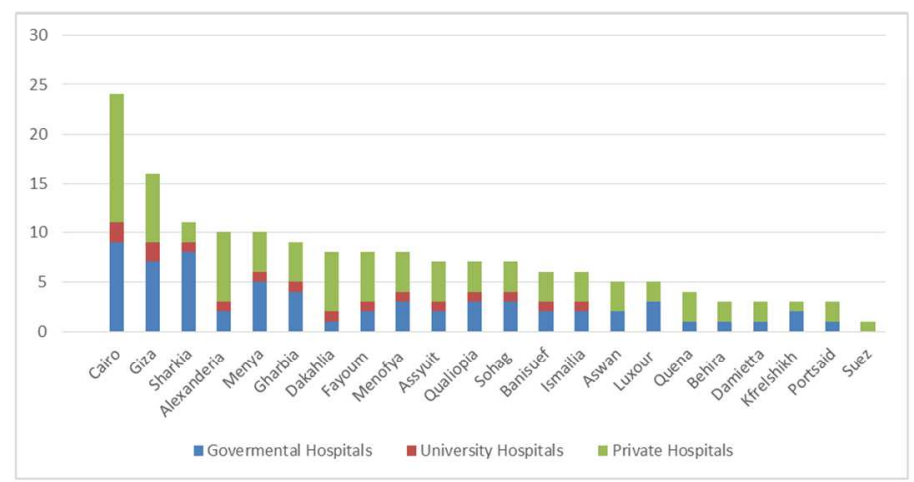

Figure 1: Distribution of participating eye hospitals per governorate and sector

$107 \times 139 \mathrm{~mm}(300 \times 300 \mathrm{DPI})$ 
Figure 2: GIS map of Egypt showing distribution of CSR in 2014

Figure 2: GIS map of Egypt showing distribution of CSR in 2014

\author{
$60 \times 80 \mathrm{~mm}(300 \times 300 \mathrm{DPI})$
}




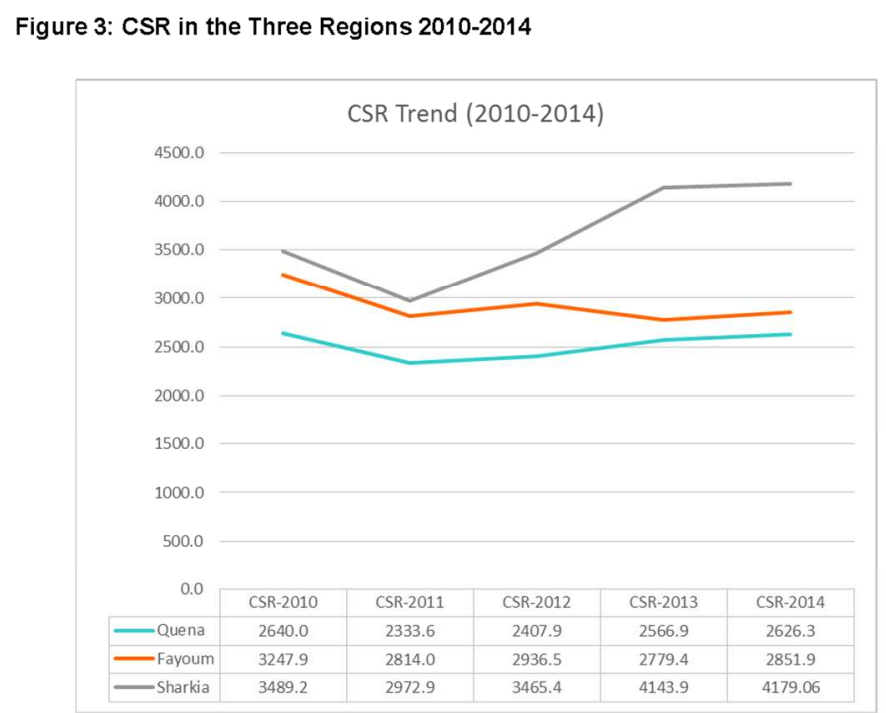

Figure 3: CSR in three regions 2010-2014

$107 \times 139 \mathrm{~mm}(300 \times 300$ DPI $)$ 
Figure 4: Turnaround time and Cataract surgical time in the government, university, and private hospitals.

Figure 4: Turnaround time and Cataract surgical rate in the government, university and private hospitals

$107 \times 139 \mathrm{~mm}(300 \times 300 \mathrm{DPI})$ 